\title{
O Método de História de Vida: Contribuições para a Compreensão de Processos de Aprendizagem nas Organizações
}

\section{The Life Story Method: Contributions to the Understanding of Learning Processes in Organizations}

\author{
Dayane Scopel Ferrazza ${ }^{1}$, Claudia Simone Antonello ${ }^{1}$
}

\author{
${ }^{1}$ Universidade Federal do Rio Grande do Sul, UFRGS, Brasil \\ Correspondência: Endereço: Av. Paulo Gama, 110, Farroupilha, Porto Alegre, RS CEP 90040-060. Tel.: 55 51 \\ 3308-6000. E-mail: daya.ferrazza@gmail.com
}

Recebido: 14 de março de 2017 Aceito: 12 de junho de 2017 Publicado: 01 de novembro de 2017

DOI: http://dx.doi.org/10.21714/1679-18272017v15n1.p22-36

\begin{abstract}
Resumo
O objetivo dessa pesquisa é apresentar o método de história de vida e discutir suas possibilidades de uso em estudos organizacionais. O estudo traz o histórico da utilização da metodologia, seus fundamentos e conceitos, permitindo ao leitor o entendimento das premissas e possibilidades da utilização do método. A utilização da história de vida nesse estudo surgiu como metodologia adequada para compreender os saberes desenvolvidos nas práticas de trabalho e nas trajetórias de vida de um grupo de cinegrafistas de uma emissora de televisão. Além das entrevistas em profundidade, utilizou-se vídeos de matérias trazidos pelos próprios entrevistados, para que eles pudessem contar sobre suas experiências a partir de uma situação real e visível. A descrição do cotidiano de trabalho dos cinegrafistas entrevistados permitiu entender a relação entre os saberes constituídos e a (re) produção das práticas e seus processos de aprendizagem, sinalizando que os saberes são complexos e estão vinculados a uma rede de práticas. Quanto ao método, essa pesquisa permitiu visualizar as histórias de vida como uma possibilidade de forma de investigação nos estudos organizacionais, permitindo ao pesquisador voltar seu olhar a uma dimensão individual que o leva para o entendimento do social respeitando as singularidades dos participantes da pesquisa.
\end{abstract}

Palavras-chave: Aprendizagem baseada em práticas. Aprendizagem organizacional. Cinegrafista. Estratégia de pesquisa. História de vida.

\begin{abstract}
The intent of this research is to present the life story method and to discuss the possibilities of its use in organizational studies. This study discusses the history of the methodology, along with its fundamentals and concepts, thus allowing the reader to understand the premises and possibilities of using the method. The use of life story in this study emerged as a proper methodology to understand the knowledge developed in the work practices and life trajectories of a group of cameramen from a television station. In addition to the in-depth interviews, videos of stories brought by the interviewees were used, so that they could narrate their experiences from a real and visible situation. The description of the daily work of the cameramen allowed viewers to understand the relationship between their ideas, methods, and learning processes, proving that the knowledge is complex and linked to a network of practices. This research allowed the visualization of life stories as an overall society, forming an investigation in organizational studies. The investigation allowed the researcher to turn his attention to each individual, leading him to the overall understanding of society, while respecting the singularities of the participants of the research.
\end{abstract}

Keywords: Practice-based learning. Organizational learning. Cameraman. Research strategy. Life's story.

Esta obra está licenciada sob uma Licença Creative Commons Attribution 3.0

\section{Introdução}

As discussões sobre a natureza e a importância da aprendizagem organizacional ganharam espaço, nos últimos anos, o que ampliou os enfoques adotados pelos estudiosos. O conceito surgiu, no início da década de 1950, mas somente a partir da década seguinte houve aumento expressivo das publicações (ANTONELLO; GODOY, 2010; 
PRANGE, 2001). Dentre as inúmeras produções teóricas sobre a aprendizagem nas organizações, diversas definições foram criadas, impossibilitando a adoção de um conceito único sobre caracterizá-la (CORREIA; FEITOSA; VIEIRA, 2010). Essa multiplicidade, como coloca Prange (2001, p. 2), "tem o sentido de uma 'selva de aprendizagem organizacional', que está tornando-se progressivamente densa e impenetrável". Para Gherardi (2001), apesar da quantidade de literatura disponível sobre o tema aprendizagem ter aumentado, a qualidade dessas produções tem caído, principalmente em função do rumo que ela tomou desde o seu início.

As mudanças pelas quais passa o ambiente organizacional contemplam questões complexas e estão inseridas em um contexto de constantes inovações tecnológicas que envolvem diversas outras temáticas. Esse novo cenário de mudanças demanda, cada vez mais, investimento e enfoque no desenvolvimento dos indivíduos e a busca de novas e constantes aprendizagens, sejam elas através de processos formais ou informais (MORAES, 2000; ANTONELLO, 2004).

O conhecimento é um tema presente, desde o período clássico grego, nos debates do contexto da administração das organizações. No âmbito acadêmico, alguns posicionamentos são destacados por estudiosos e trazem diferentes noções sobre o conhecimento, dentre eles: a gestão do conhecimento, que tem como objetivo prever e proporcionar o máximo retorno do investimento realizado, e a perspectiva dos saberes em prática, que estende o olhar para um entendimento de como o conhecimento implica as práticas de trabalho dos colaboradores de uma organização. Independente da noção que se assuma como linha orientadora, é incontestável a importância do conhecimento para as organizações (KOLOSKOV, 2010).

A abertura dos estudos organizacionais para uma maneira alternativa de pensar a aprendizagem e o conhecimento proporcionou o crescimento do interesse pela abordagem baseada em práticas, impulsionado tanto por acadêmicos quanto por profissionais que estudam e vivenciam o tema. $\mathrm{O}$ principal ponto é que, em decorrência dessas novas visões sobre o conhecimento e sobre a aprendizagem, ambos deixam de ser concebidos como algo que acontece individualmente e passam a ser observados e estudados como um processo social (NICOLINI et al., 2003), a partir do qual mente e corpo, pensar e agir, indivíduo e organização não são tratados de forma dicotômica (GHERARDI, 2000).

Através da abordagem baseada em práticas, abre-se para o pesquisador a possibilidade de investigar, com mais profundidade, o que ocorre e como ocorrem as relações que se estabelecem dentro do campo a ser pesquisado. Por meio das práticas é possível analisar o processo resultante da conexão existente entre atores, artefatos, processos e sistemas.

No presente estudo, voltou-se o olhar para as mudanças das tecnologias que envolvem as transmissões de televisão e as captações de imagem para o jornalismo, principalmente, porque revelam um cenário desafiador para os profissionais do meio, os quais precisam se adaptar a uma tecnologia cada vez mais acessível ao público em geral e a um conhecimento amplamente difundido e disponível para os interessados. Frente a um cenário de tantas inquietações, indaga-se como estes indivíduos que optam por utilizar a captação de imagens como profissão conseguem assumir uma posição de destaque?

Por um lado, é sabida a importância da atividade dos cinegrafistas no produto final oferecido aos telespectadores, por outro, esses mesmos profissionais ainda não possuem merecido destaque dentro das organizações em que trabalham, sendo sua posição considerada mais operacional dentro do quadro funcional. Um dos motivos pelos quais isso ocorre é sua atuação restrita aos bastidores, não possuindo relação direta com os telespectadores e com o conteúdo jornalístico ou de entretenimento. Outros motivos a ressaltar são a falta de legislação específica atualizada para esses trabalhadores e de qualificação formal, que possibilite uma formação direcionada para essa área de atuação.

Com o objetivo de explorar temas como este, que orientam o olhar do pesquisador para a compreensão de fenômenos complexos, surgem e se fortalecem novos métodos de investigação, especialmente os qualitativos e interpretativos, permitindo o emprego de diferentes perspectivas sob um olhar plural e não reducionista. A utilização da história de vida é uma destas alternativas. Embora já venha sendo utilizada há várias décadas em diversos campos das ciências sociais, sua aplicação nos estudos organizacionais é recente.

Assim, o presente artigo tem como objetivo demonstrar as possibilidades da abordagem da história de vida como uma estratégia metodológica que pode favorecer o estudo de processos de aprendizagem dos cinegrafistas e os estudos baseados em prática. Embora cada história de vida traga em suas narrativas um olhar individual, a vida humana é repleta de outras conexões e carregada de diversas informações sobre a sociedade em que o sujeito está inserido. Desta forma, a abordagem de história de vida permite levar o escopo de estudo de processos de aprendizagem do âmbito individual para o social, possibilitando não só a compreensão da construção dos aprendizados pelo individuo, mas suas relações com o campo organizacional e seu contexto macro.

No decorrer das páginas será introduzida a história de vida - histórico e conceito - e algumas técnicas utilizadas 
http://www.revista.ufpe.br/gestaoorg

para a aplicação deste método - entrevistas e utilização de vídeos. Posteriormente será apresentada uma alternativa para análise das histórias de vida, seguido por um caso real de história de vida realizado a título de ilustrativo e suas contribuições para os estudos da aprendizagem baseada em práticas dos cinegrafistas.

\section{A História de Vida em Pesquisas Qualitativas na Administração}

A história de vida é uma forma de investigação qualitativa (CHASE, 2008), capaz de fornecer uma alternativa às formas tradicionais de metodologia científica (JAIME; GODOY; ANTONELLO; 2007). Segundo Polkinghorne (1995), o interesse crescente dos pesquisadores a respeito de formas narrativas deve-se à sua forma linguística, apropriada para demonstrar a existência humana como uma ação situada. Para o autor, a narrativa é visualizada no sentido de uma 'história' (story) que evidencia a visão de mundo de uma cultura, integrando diversos eventos em um episódio único.

A história de vida como abordagem metodológica foi incluída no meio acadêmico anteriormente às definições feitas por Denzin da Escola de Chicago, em 1920, e foi desenvolvida por Znaniescki, na Polônia. As primeiras definições de história de vida têm suas origens, na década de 1920, em abordagens feitas por antropólogos para descrever culturas americanas nativas. A década seguinte enfatizou análises de histórias de vida, interligando a antropologia e a psicologia. No entanto, foi apenas durante a década de 80 que o método estabeleceu estratégias de análise do vivido, tornando-se um método reconhecido e despertando interesse por sua aplicação para a coleta de dados sobre o homem, em um contexto de relações sociais (HATCH; WISNIESKI; 1995).

Considerando a denotação dos termos, Atkinson (2003) afirma que história de vida (history e story) e história oral são diferentes expressões usadas para definir o mesmo elemento. Em 1970, o sociólogo americano Denzin fez a distinção entre as terminologias life story (história ou relato de vida) e life history (estudo de caso clínico). Para ele, life story, entendida como história ou o relato de vida, é aquela que descreve a história de vida tal qual contada pela pessoa que a vivenciou, não havendo interesse do pesquisador em confirmar a autenticidade dos fatos, pois o objetivo é visualizar o ponto de vista do sujeito narrador. A life history, como estudo de caso clínico, compreende, além da narrativa, um estudo de todos os documentos que possam ser consultados, caracterizandose como uma técnica de estudo de caso clínico (BERTAUX, 1980).

Ainda na diferenciação dos termos, Bornat (2004) expõe aproximações e diferenças existentes entre os termos história oral e história de vida. A similaridade encontra-se na relação entre o sujeito, o entrevistador e o assunto: ambas as histórias têm foco na ideia de que o entrevistado é um participante ativo no processo, ou seja, seu desejo de participação e sua consciência se tornam essenciais nos relatos que ele oferece. A diferença sutil entre os termos está relacionada, principalmente, ao modo de aproximação e de coleta de dados, no qual a história de vida foca a vida de um indivíduo e sua história, sob um ponto de vista que permita ao pesquisador obter o entendimento de determinado processo social.

A história de vida pode ser considerada um "relato de um narrador sobre sua existência através do tempo, tentando reconstituir os acontecimentos que vivenciou e transmitir a experiência que adquiriu" (QUEIROZ, 1988, p, 20). Queiroz (1988) diferencia história oral e história de vida. Ele explica que a primeira é qualquer relato oral e pode abranger relatos de lendas e transmissão de cultura, e que a segunda possui maior enfoque no indivíduo e em sua existência. Para Chase (2008), a história de vida é um tipo de narrativa extensa, que se apresenta em forma oral ou escrita, e abrange toda a história do indivíduo, desde seu nascimento até os dias atuais. Segundo Denzin (1989), uma história de vida - ou história pessoal, como é denominada em alguns casos - é um registro escrito da vida de uma pessoa, tendo por base conversas e entrevistas.

Além das diferenças entre as nomenclaturas, é importante também delimitar o período de vida que se pretende estudar: com base na vida do sujeito como um todo ou apenas em aspectos que possibilitem a compreensão e a problematização do tema de pesquisa. Plummer (2001) sugere essa diferenciação através dos conceitos de histórias longas e curtas. Para ele, histórias longas consistem na essência do método, são reunidas em períodos extensos de pesquisa e fornecem uma investigação detalhada sobre o mundo do indivíduo. As histórias curtas, mais usuais em estudos organizacionais, costumam ser captadas através de entrevistas em profundidade, focadas em aspectos relevantes do que o pesquisador pretende investigar e na comparação com outras histórias.

Segundo Josso (1999), há expressivo interesse pela abordagem biográfica nos estudos dos processos de aprendizagem, na área da Educação. No entanto, considerando o campo dos estudos organizacionais de modo geral, a aplicação desse método ainda é escassa. O I Encontro de Ensino e Pesquisa em Administração e Contabilidade, em 2007, trouxe evidências de que essa abordagem metodológica está recebendo maior atenção, sendo enfatizada nos trabalhos desenvolvidos por Jaime, Godoy e Antonello (2007), Mageste e Lopes (2007), Perazzo e Bassi (2007) sobre as possibilidades de uso da história de vida e da história oral nos estudos organizacionais e em administração. 
A metodologia de história de vida fornece ao pesquisador dados que podem evidenciar como, ao longo do tempo, se constituiu a personalidade do sujeito pesquisado (QUEIROZ, 1988), auxiliando a compreensão e a análise dos processos de aprendizagem sob a perspectiva psicológica. Essa perspectiva psicológica trata da aprendizagem como um "processo pelo qual mudanças relativamente permanentes ocorrem em potencial comportamental como resultado da experiência" (ANDERSON, 1995, p. 4 apud MAIER et al., 2001). Assim, os processos de aprendizagem podem ser identificados através dos relatos de história de vida.

"Não é só a riqueza objetiva do material primário que nos interessa, mas também e sobretudo a sua pregnância subjetiva no quadro de uma comunicação interpessoal complexa e recíproca entre o narrador e o observador" (FERRAROTI, 1988, p. 25). A história de vida permite, portanto, não somente analisar a visão do indivíduo com suas especificidades, como também analisar essa visão aliada a uma perspectiva social, ou seja, captar "o que sucede na encruzilhada da vida individual com o social" (QUEIROZ, 1988, p. 36). Há um papel importante do pesquisador em desvendar as histórias de vida levando em consideração e fazendo as devidas relações com os acontecimentos sociais, para ir além do relato individual transmitido ao pesquisador.

Através dos relatos de vida, é possível esclarecer peculiaridades inerentes ao processo de aprendizagem por reflexão. Para compreendê-las faz-se necessário entender seu contexto cultural e histórico, pois as experiências de cada indivíduo não são produções exclusivas de si, mas derivadas do contexto que o cerca (DENZIN, 1989).

Embora cada história de vida contenha uma ótica individual, a vida humana engloba uma série de dimensões e traz informações sobre a sociedade em que esta pessoa está inserida, sobre seus valores sociais e culturais, sobre seu contexto histórico e econômico, sobre as organizações e instituições de sua época, entre outros aspectos. Desta forma, a abordagem de história de vida permite levar o escopo de estudo de processos de aprendizagem do âmbito individual para o social, possibilitando uma compreensão destes processos contextualizando-os não apenas no campo organizacional, mas no macro contexto em que ocorrem (CLOSS; ANTONELLO, 2012, p. 108).

Além do evidente desafio do método de história de vida em representar aspectos individuais ao contexto mais amplo da sociedade (HATCH; WISNIEWSI, 1995), há também aspectos relacionados à aplicação da metodologia, concernentes principalmente ao tempo necessário para realizar a pesquisa, que envolve diversas entrevistas, sua transcrição e análise.

O número de participantes de uma pesquisa varia muito: há estudos baseados em apenas uma história de vida e outros em até 800 casos. No entanto, a maioria das narrativas possui um aspecto comum quanto ao número de participantes: contemplam menor número de sujeitos pesquisados em relação a outros métodos qualitativos (CHASE, 2005).

A pesquisa qualitativa não tem, assim, a pretensão de ser representativa no que diz respeito ao aspecto distributivo do fenômeno e se alguma possibilidade de generalização advier da análise realizada, ela somente poderá ser vista e entendida dentro das linhas de demarcação do vasto território das possibilidades (PAULILO, 1999).

Para realizar o estudo qualitativo com a devida profundida, a história de vida propõe uma escuta atenciosa e participativa, criando uma relação de cumplicidade entre o pesquisador e os sujeitos pesquisados, que devem ser capazes de reconstituir seu percurso (NOGUEIRA, 2004). Para Paraná (1996, p. 317), a história de vida é uma tentativa de oferecer escuta e "de dar voz àqueles cujo discurso foi calado".

Partindo do resgate teórico metodológico disposto até então e da caracterização do percurso da história de vida nos estudos organizacionais, foi realizada uma pesquisa adotando a história de vida como método de pesquisa, incorporando trechos relevantes das vidas dos indivíduos pesquisados, na tentativa de reconstituir os acontecimentos que presenciaram e transmitir a bagagem adquirida (PLUMMER, 2001; QUEIROZ, 1988). O recurso adotado foi pelas histórias curtas para sustentar essa contextualização. A opção por histórias curtas, no método de história de vida, se justifica pelo interesse dessa pesquisa em focar em apenas um dos aspectos da vida dos sujeitos pesquisados: sua trajetória profissional. Demonstrações de sentimento e aspectos psicológicos explanados durante as entrevistas foram levados em consideração quando pertenceram ao contexto profissional do sujeito. Dessa forma, as entrevistas foram conduzidas de forma a focar na experiência profissional e não o de trazer aspectos que não estivessem relacionados com a abordagem pretendida. Como forma de detalhar os passos seguidos para realização da pesquisa, esse artigo também tem como objetivo demonstrar as técnicas que foram adotadas para realizar essa pesquisa. 
http://www.revista.ufpe.br/gestaoorg

\subsection{Entrevistas em profundidade como ferramenta de pesquisa}

A coleta de dados dessa pesquisa, baseada na história de vida, foi a entrevista mediante um roteiro não estruturado, como orienta Fontana e Frey (2008) e Lankshear e Knobel (2008). A entrevista é considerada uma forma de interação social, que permite ao pesquisador obter dados da vida social dos sujeitos entrevistados e identificar diferentes formas de descrição dos fenômenos estudados (FONTANA; FREY, 1994; DUARTE, 2006). "Mais especificamente, é uma forma de diálogo assimétrico, em que uma das partes busca coletar dados e a outra se apresenta como fonte de informação" (GIL, 2008, p. 109).

A concretização do método de história de vida, pela ótica de histórias curtas, se deu através de entrevistas em profundidade, sem roteiro estruturado e com a formulação de apenas uma pergunta-chave, para nortear os discursos dos sujeitos de pesquisa. De acordo com a delimitação desse estudo, que tem como recorte a trajetória profissional dos participantes, a questão norteadora os instigará a falar abertamente sobre sua trajetória profissional. Queiroz (1988) apresenta, em seu discurso, pontos sobre a interferência do pesquisador durante a entrevista, que deve ser mínima, de modo a permitir ao entrevistado determinar o que é relevante ou não contar. A realização das entrevistas através de uma abordagem mais ampla abrange dois aspectos importantes, no método de história de vida: "quem decide o que vai relatar é o narrador [...] e nada do que relata pode ser considerado supérfluo, pois tudo se encadeia para compor e explicar sua existência” (QUEIROZ, 1988, p. 21).

Para a realização da primeira entrevista, uma questão norteadora foi formulada, que buscou identificar a trajetória de vida dos entrevistados, segundo sua percepção: Eu gostaria que você me contasse sua experiência de vida, desde a infância até os dias de hoje, relatando experiências que trouxeram aprendizagens importantes para sua profissão de cinegrafista. Você pode iniciar por onde quiser, sem colocar as coisas em ordem e também não precisa ter pressa nem resumir nenhum fato.

Após a transcrição da primeira entrevista e a reflexão sobre seu conteúdo, buscou-se, nas entrevistas posteriores com o sujeito pesquisado, esclarecer pontos que tenham suscitado dúvidas e trazer à tona alguns questionamentos importantes para a investigação proposta.

\subsection{Utilização de vídeos na entrevista}

Segundo Frisch (2008), a história de vida tem sido cada vez mais entendida como uma abordagem que associa diversas estratégias de coleta de dados, na busca de melhor compreensão da realidade estudada. Dentre estas estratégias, cito o uso de fotografias, a gravação, a pesquisa documental, as entrevistas e o uso de diário de campo (JAIME; GODOY; ANTONELLO, 2007).

De forma a aliar o contexto no qual os sujeitos de pesquisa vivem às estratégias metodológicas utilizou-se como recurso a imagem em movimento, mais especificamente durante as entrevistas em profundidade. A utilização da imagem justifica-se pela sua onipresença na sociedade atual (BANKS, 2009), auxiliando na descrição mais detalhada do que foi colhido em campo (BECKER, 1997).

A segunda boa razão para o pesquisador social querer incorporar a análise de imagens é que o estudo de imagens ou um estudo que incorpora imagens na criação ou coleta de dados pode ser capaz de revelar algum conhecimento sociológico que não é acessível por nenhum outro meio (BANKS, 2009, p. 18).

O mundo em que vivemos é intensamente influenciado pelos meios de comunicação, principalmente a televisão, que assumiu um papel importante no acesso à informação e ao entretenimento. Os meios de comunicação têm seus resultados, muitas vezes, dependentes de elementos visuais, “consequentemente, 'o visual' e 'a mídia' desempenham papéis importantes na vida social, política e econômica. Eles se tornaram 'fatos sociais', no sentido de Durkheim. Eles não podem ser ignorados" (LOIZOS, 2002, p. 138).

A utilização de imagens na coleta de dados é uma forma de o pesquisador fazer com que os sujeitos de pesquisa reflitam sobre elas. Banks (2009) afirma que ainda existem poucos métodos novos de coleta de dados visuais, mas que as técnicas existentes - filme e foto-elicitação - "são realmente maneiras de estender os métodos sociológicos mais comuns de entrevistas" (BANKS, 2009, p. 81). A elicitação será adotada, nessa pesquisa, por envolver o uso de materiais visuais que podem suscitar comentários, memória e discussões, no decorrer de uma entrevista com roteiro não estruturado (BANKS, 2009).

A elicitação através de fotografias é mais usada do que vídeos e filmes, principalmente pela facilidade de manuseio e de interação. O trabalho de Stephanie Krebs, sobre a dança-drama tailandesa conhecida como Khon, realizado no início da década de 1970, foi um dos primeiros trabalhos a exemplificar o uso de filmes para obter informações dos sujeitos entrevistados, ainda que de maneira amadora.

A utilização de imagens em pesquisas sociais pode provocar sentimentos diversos. Além de considerar a 
narrativa interna da imagem, ou seja, a história que aquela imagem está contando ao espectador, há também duas narrativas externas que podem ser consideradas. Um é em relação ao contexto imediato - aqui-agora - e aos sentimentos envolvidos no momento da entrevista, a outra é o contexto - ali-então - da produção original daquela imagem.

Para os sujeitos dessa pesquisa, as imagens possuem um papel significativo em suas vidas, influenciando sua forma de agir, tanto no aspecto profissional quanto pessoal. Assim, recorreu-se às gravações realizadas pelos próprios sujeitos pesquisados para nortear uma das entrevistas que compõe o conjunto de entrevistas em profundidade. Ao invés de um questionamento norteador, os indivíduos foram instigados a contar, da maneira que consideraram relevante, a construção, a vivência e os percalços da realização de determinada imagem. A fim de trazer à tona os sentimentos e aprendizados envolvidos no material produzido por eles mesmos, a indagação a seguir foi proposta aos entrevistados: Conte-me quais são suas percepções sobre o conteúdo visualizado, considerando todos os aspectos envolvidos no momento da captação das imagens. Fique à vontade para falar sobre os sentimentos, os aspectos técnicos de equipamento ou os conhecimentos necessários para este trabalho.

Os vídeos foram trazidos pelos cinegrafistas na segunda entrevista. Ao final da primeira, os participantes foram instigados a trazerem matérias gravadas por eles e que os remetessem a alguma experiência marcante, podendo ser imagens que não tinham sido executadas como imaginavam, matérias que ganharam destaque ou outras mais triviais. Todos os entrevistados trouxeram cerca de três matérias, predominando produções mais recentes e compatíveis com as aptidões de cada um.

Com a utilização dos vídeos, a dinâmica das entrevistas foi um pouco diferente da entrevista inicial. Enquanto os vídeos eram assistidos, os próprios cinegrafistas pausavam a projeção para fazer comentários espontaneamente ou os faziam durante a apresentação do vídeo, explicando o que acontecia e por que as imagens estavam daquela maneira. A média de duração da primeira entrevista foi de 30 minutos, as entrevistas que tiveram a projeção de vídeo duraram cerca de uma hora. Assim, percebi que a materialização do discurso, através de seu próprio conteúdo, despertava nos sujeitos desse estudo maiores domínio e segurança do que somente a fala.

\section{Método de Análise das Histórias de Vida}

Uma das abordagens destacadas por Denzin (1989) para a organização e a interpretação das informações obtidas através da história de vida é a estratégia interpretativa, a qual foi adotada nesta pesquisa. Para Gil Flores (2008), os procedimentos interpretativos de análise estão relacionados às estratégias que atuam sobre dados qualitativos e partem do pressuposto que a realidade social é múltipla, modificável e resultado de uma construção social. A análise dos dados se adapta aos objetivos dessa pesquisa, pois não se busca apenas descrever os achados obtidos em campo, mas igualmente a produção de sentido que responda a pergunta inicial (MERRIAM, 1998).

O processo de interpretação é concebido, aqui, como um processo de produção de sentido. O sentido é, portanto, o meio e o fim de nossa tarefa de pesquisa. Como atividade-meio, propomos que o diálogo travado com as informações que elegemos como nossa matéria-prima de pesquisa nos impõe a necessidade de dar sentido: conversar, posicionar, buscar novas informações, priorizar, selecionar são todos decorrências do sentido que atribuímos aos eventos que compõem o nosso percurso de pesquisa (SPINK; LIMA, 2013, p. 82).

Uma recomendação comum entre alguns autores é a realização de leituras atentas do material coletado e transcrito, de modo a orientar a decisão sobre as principais abordagens a serem exploradas, tendo em vista sempre o objetivo principal do estudo (DEMARTINI, 1988). A primeira entrevista já pode revelar aspectos importantes que não foram contemplados pelo pesquisador no planejamento das entrevistas e que deverão ser levados em consideração. Não é possível, portanto, perceber momentos distintivos entre o levantamento das informações e a interpretação, pois, durante todo o processo, o pesquisador está imerso no processo da própria interpretação (MERRIAM, 1998; DEMARTINI, 1988).

O pesquisador está, desde a realização da primeira entrevista, analisando as informações que lhe chegam e está, até a última entrevista, inovando o seu referencial teórico e a sua técnica de pesquisa; ele lida, desde o início, com o geral e com o particular, na medida em que cada história de vida é um todo que se apresenta (DEMARTINI, 1988, p.70).

A análise inicia-se de fato com a imersão nas informações recolhidas, "procurando deixar aflorar os sentidos, sem encapsular os dados em categorias, classificações ou tematizações definidas a priori" (SPINK; LIMA, 2013, p. 83). Segundo Demartini (1988), a riqueza proveniente do referencial teórico, através da história de vida, ocorre pelo envolvimento e pelo questionamento recorrente sobre a literatura e sua relação com o campo. Para Spink e Lima (2013), é no momento da análise que podem surgir confrontos entre os sentidos construídos 
durante o processo de pesquisa e os conhecimentos decorrentes das teorias-base.

Após a conclusão de todas as entrevistas e de sua transcrição, muitas leituras foram realizadas, na busca do entendimento completo de histórias não contadas de forma linear. Diferentemente de um método tradicional, na história de vida é preciso ouvir e interpretar uma narrativa de cada vez, de maneira isolada, com o intuito de encontrar sua relevância pessoal e estabelecer conexões (CHASE, 2005; ATKINSON, 2002). Cada história de vida foi, portanto, tratada individualmente, considerando sua totalidade e buscando explorar seus diversos significados (DENZIN, 1989).

Após o entendimento da história de cada participante da pesquisa, destacaram-se trechos dos depoimentos coletados, tendo em vista o problema de pesquisa levantado, constituindo-se então categorias amplas. O conjunto de informações foi analisado, identificando-se semelhanças e diferenças entre os discursos e os interpretando com base nos referenciais teóricos existentes e nos novos referenciais identificados que pudessem auxiliar a compreensão dos objetivos de pesquisa propostos. O retorno aos relatos completos, com base nos trechos analisados, ocorreu recorrentemente, de forma a não perder de vista o contexto explicitado pelo entrevistado, no momento da fala.

A partir da contextualização de todo percurso metodológico sobre a utilização da história de vida, a seção posterior irá trazer o relato de dois dos entrevistados e suas contribuições para os estudos da aprendizagem baseada em práticas.

\section{Colocando a Câmera no Ombro: Trajetórias de Vida dos Cinegrafistas}

Antes de mergulhar na análise dos resultados desta investigação, procurou-se sintetizar as histórias de vida de cada entrevistado, pois, como afirma Queiroz (1988), uma das contribuições dos relatos das experiências é a possibilidade de mostrar como, ao longo do tempo, formou-se a personalidade do narrador. Dessa forma, a partir da história de dois entrevistados que serão aqui apresentados a título de ilustração, o leitor poderá conhecer o contexto em que cada um está inserido, sua trajetória e suas ideias gerais sobre a profissão.

\subsection{A trajetória de vida de Pedro}

A história de Pedro com a televisão teve início com a fotografia. Seu pai era professor e, devido ao baixo salário, começou a tirar fotos de casamentos e de turmas de colégio. Com dois empregos e uma faculdade, o pai de Pedro estava pouco em casa e eles se viam com pouca frequência, porém quando seu pai estava "mexendo no equipamento e tal, eu ficava sempre na volta ali, e meu interesse por fotografia começou naquela época já".

Aos seis anos de idade, Pedro ganhou sua primeira câmera fotográfica. Com ela vieram a curiosidade pela arte da imagem e o interesse em desvendar os mistérios daquele equipamento. Junto a seu pai, Pedro mexia constantemente nas câmeras e inclusive o auxiliava na revelação das fotos, que era feita em um laboratório organizado no banheiro da casa onde moravam.

São coisas que vão te marcando assim como criança. Eu tava sempre perto do meu pai, sempre junto com ele, sempre vendo o que ele tava fazendo. E isso é uma coisa que despertou assim meu interesse pela imagem assim, pela fotografia (Pedro).

Com o passar do tempo, Pedro se envolveu com o serviço militar. Quando saiu do quartel, em 1988, por indicação de um tio que trabalhava em uma emissora de televisão da cidade, nela se tornou operador de videoteipe (VT) ${ }^{\mathrm{i}}$. No entanto, um ano após, a função em que trabalhava foi extinta e "eu era um guri, não tinha família nada, outras pessoas que trabalhavam ali tinham mais experiência do que eu, e família né. Aí saí, fiquei um ano fora".

Após trabalhar um ano em outra organização, a emissora de televisão em que atuara anteriormente entrou em contato com Pedro e ofereceu-lhe vaga de auxiliar técnico, no almoxarifado de equipamentos. "Comecei a ter o contato direto com as câmeras que a gente trabalha né. Aí comecei a mexer, comecei a olhar, ler manuais, e pegar dicas com um ou outro colega assim".

Apesar da dificuldade de extrair informações dos colegas, Pedro foi se interessando cada vez mais pela profissão e pelas imagens da televisão. Um dia seu colega cinegrafista faltou e era necessário fazer algumas imagens importantes sobre o trajeto de turbinas que haviam chegado à cidade.

Eu me ofereci. Aí o diretor da época, o diretor de jornalismo, aí ele disse: 'Ah vai, vai lá, que no mínimo que vai fazer é não poder usar, mas se tu não for a gente não vai ter'. Aí fui, fiz, deu certo, apesar do nervosismo e tal, sabe aquela coisa (Pedro).

Durante três anos, Pedro cobriu as férias de seus colegas e se prontificava a fazer matérias, quando algum cinegrafista faltava. Em 1994, Pedro foi promovido a cinegrafista e começou uma sólida trajetória, na mesma emissora de televisão em que iniciara. Seu interesse pela profissão resultava em muita pesquisa e em muitos 
estudos. Junto com a cinegrafia, "aprofundei também o meu hobby pela fotografia. Então uma coisa foi se juntando na outra sabe, e hoje a gente faz essas Escolas de Vídeo aqui né, eu dou aula também, eu dou aulas lá como operador, pra cursos de operador de câmera".

O interesse de Pedro por tecnologia é tão grande que ele vive conectado, experimentando novas técnicas de captação de imagem. Um exemplo disso foi a descoberta de um aplicativo de celular que fazia imagens em timelapse $^{i i}$. Depois de testar o aplicativo com um vídeo de flor de cactos se abrindo, Pedro arriscou fazer um vídeo do nascer do sol. "Botei o telefone numa área dos fundos que eu tenho na minha casa que é leste né. Então deixei de noite gravando e de manhã o sol nasceu, botei um carregador nele pra ele aguentar e fícou um vídeo lindo". Entretanto, depois da gravação desse vídeo, suas fotos estavam sempre aparecendo com um risco e então Pedro descobriu que fazer imagens diretas do sol queima o sensor da câmera, fato que para ele parecia ter sido superado com câmeras modernas.

Ele (editor) abriu (a matéria) com um clipe em time-lapse e tudo isso aí eu fiz baseado no que eu aprendi no telefone. Porque quando eu peguei a câmera assim, o princípio era o mesmo sabe, eu descobri aonde era, fiz uma pesquisa pra saber de, que tinha algumas coisas diferentes que na câmera tu poderia colocar mais frames sabe, pra ti fazer esses time-lapse aí. E aí eu comecei a fazer, e aí eu comecei a fazer, uma coisa que eu aprendi no telefone (Pedro).

O resultado das experiências de Pedro, externas à televisão, refletiu-se diretamente na construção de seu trabalho na emissora, e adveio de um dos vídeos apresentados durante sua entrevista: um time-lapse do nascer do sol em Porto Alegre. Além desse vídeo, Pedro também trouxe um de maior duração: dez minutos de matéria. Durante a projeção, ele contou sobre como aprendeu a utilizar diferentes equipamentos em situações inusitadas. A matéria deste vídeo era sobre o tipo de produção e permitia ao cinegrafista abusar tanto dos tipos de câmeras como das luzes, tendo, portanto, a possibilidade de aplicar várias técnicas e usar diferentes modos de gravar. O último vídeo trazido foi uma matéria feita para um noticiário local, em que o cinegrafista continuou gravando após a entrevista terminar e teve a habilidade de captar momentos do entrevistado que repercutiram nacionalmente. Mais do que acreditar que aquela cena poderia render mais do que uma entrevista, o entrevistado trouxe esse conteúdo para mostrar como é importante o envolvimento do cinegrafista em todos os âmbitos, pois, para ganhar espaço com aquele conteúdo, Pedro precisou insistir junto à editoria do programa para visualizarem suas imagens.

São situações inusitadas e experiências marcantes em sua trajetória de vida que tornam Pedro referência para todos os demais entrevistados. Pedro aliou o interesse pelas imagens, pela televisão e pela fotografia à facilidade de ensinar. Sua didática foi reconhecida espontaneamente pelos demais entrevistados. Hoje ele participa de escolas e formata treinamentos dentro da própria emissora.

\subsection{A trajetória de vida de Tarantino}

"Quando eu era menino, todo mundo na minha época queria ser jogador de futebol, outros queriam ser pilotos de Fórmula 1, e eu desde muito menino mesmo, desde os meus 14 anos, eu já queria trabalhar em televisão" (Tarantino).

Esse é o começo da trajetória de Tarantino, que desde muito cedo com a convicção do profissional que se tornaria quando maior, trilhou e percorreu um caminho para se preparar e assumir a profissão de cinegrafista. Tarantino iniciou como office boy em uma emissora de televisão, tendo assim o primeiro contato com o dia a dia do jornalismo e com os equipamentos. Ainda como office boy aprendeu a ser cinegrafista, com colegas de trabalho que tiveram importante papel nessa trajetória.

Tenho bons amigos que começaram a dizer: 'tu não poder ser boy sempre', e diziam pra eu aprender, e fui aprendendo no dia a dia, saindo com as equipes pra rua, sem o compromisso de fazer, só saia pra ver como é que era a rotina, e aí o profissional passava o equipamento pra mim, e me supervisionando, me ajudando, como fazer, como agir, como me comportar com a equipe (Tarantino).

Durante seis anos, Tarantino trabalhou como office boy da emissora, buscando sempre o contato com as câmeras, ainda que indireto, recebendo o apoio dos colegas. A promoção de office boy para cinegrafista "tava fora de questão, não tinha como", pois, na época, "só pessoa muito qualificada entrava, era uma época que se exigia muito do profissional". A alternativa que encontrou foi uma transição para operador de VT, pois como "era uma profissão que já tava a beira da extinção, alguns profissionais já tavam se aposentando (...). Eu não ia conseguir dar um salto tão grande, eu precisava desse degrau". Percorrer esse caminho não foi fácil, mas devido à aposentadoria de alguns operadores de VT, foram "surgindo oportunidades de fazer freelance pra poder aprender e assim fui indo". 
http://www.revista.ufpe.br/gestaoorg

Antes ser office boy, Tarantino nunca havia tido contato com uma câmera. Apesar de gostar muito de televisão e ter certeza de onde queria chegar, o contato com a tecnologia de como fazer cinegrafia ele foi ter em seu primeiro trabalho na televisão. Após o horário de expediente, quando as pessoas já tinham saído da emissora, Tarantino pegava a chave da sala de equipamentos, montava o equipamento sozinho, gravava algumas imagens e depois assistia.

Durante muito tempo, Tarantino trabalhou como operador de VT e, após seis anos na primeira emissora de televisão em que trabalhou como office boy, ele migrou para a segunda emissora, juntamente com um grupo de profissionais que estava fazendo essa mesma movimentação. Por causa de sua experiência como freelance de operador de VT, Tarantino conseguiu ir para essa emissora como operador de VT e assim iniciar sua trajetória como cinegrafista. O trabalho como operador de VT deu a ele a oportunidade de conviver com pessoas que "eram meus professores, que foram meus professores" e que são, até hoje, sua inspiração no mundo do jornalismo.

Lá foi muito mais fácil passar de operador de VT pra cinegrafista, porque o público lá não era tão qualificado como era aqui, que a exigência era muito maior, padrão nacional. Mas lá eu consegui mostrar uma coisa que eu realmente nasci pra fazer, fazendo bem ou fazendo mal, mas foi o que eu nasci pra fazer, eu sabia que isso ia dar certo, e deu certo (Tarantino).

A chance para ser cinegrafista apareceu tanto porque Tarantino conseguiu mostrar que "podia fazer imagens", como por ter o apoio de pessoas que acreditavam nele e queriam the dar oportunidades. "Eu aproveitei bem a oportunidade, agarrei com tudo porque eu sabia que esse era meu destino". Apesar da pouca experiência em captação de imagens, Tarantino era muito jovem quando começou na segunda emissora e estava consciente de que ainda não tinha a experiência necessária. Pela vontade de fazer aliada ao vigor físico, destacou-se, no trabalho, em relação aos demais profissionais.

Na segunda emissora, já atuando como cinegrafista, Tarantino trilhou um caminho que lhe permitiu voltar para a emissora onde sua história começara e que "é o que eu sempre quis pra mim". Certo de sua vocação, Tarantino conquistou seu objetivo e hoje afirma: "eu sempre quis trabalhar onde tô trabalhando e fazer o que eu faço".

Dentre as diversas histórias de sua carreira, Tarantino destaca uma das primeiras matérias - "que deu estresse" cujo objetivo era gravar um boletim durante a procissão de Nossa Senhora de Navegantes. Inconsciente dos impactos que sua ansiedade poderia causar, ele disse ao repórter que não havia possibilidade de errar naquela gravação. Seu posicionamento impositivo deixou o repórter nervoso e os erros foram tantos que a procissão passou por eles sem que o boletim pudesse ser gravado. Hoje, ao lembrar o ocorrido, Tarantino reconhece que "eu era muito afoito, muito temperamental (...) impus essa condição a ele, e do meu modo de ver eu não ia errar".

Com o passar do tempo, Tarantino foi se desenvolvendo cada vez mais e todo o preparo e dedicação, durante a carreira na televisão, transformaram-se em prêmios e matérias reconhecidas. Durante a entrevista com apresentação dos vídeos, ele se mostrou muito preocupado em trazer para discussão matérias que valorizassem seu trabalho e mostrassem o reconhecimento dos anos de dedicação à emissora. Desde matérias sobre a natureza, em que teve que aprender a lidar com um ambiente diferente do usual, até coberturas investigativas e especiais, todas as matérias trazidas remetiam a um momento de vitória. Nos relatos, Tarantino contou sobre como passou por situações difíceis durante algumas coberturas, que abrangeram desde matérias sobre prostituição infantil até sobre a pobreza e o impacto na saúde. Nestas ocasiões, ele vivenciou realidades que nunca antes imaginara, às quais precisou se adaptar rapidamente e fazer com que elas não influenciassem seu comportamento como cinegrafista nem afetassem seu emocional.

O desafio de hoje é o mesmo que eu tinha a mais de 20 anos atrás (...) eu não me dou o direito de achar que eu já domino totalmente, eu acho que todo dia eu tô aprendendo, pra eu me manter atento. E o maior desafio é o mesmo que era antes, relacionamento, relacionamento com repórter, com equipe, isso é difícil, era e é difícil ainda, então é um exercício cotidiano, um exercício diário (Tarantino).

Confiante de ter escolhido a profissão certa, Tarantino afirma que quer se aposentar fazendo o que faz hoje, "que eu chegue com saúde, com a coluna boa, com o olho bom". Ciente de que os esforços necessários da profissão não eram naturais para o corpo - uma câmera pesa cerca de doze quilos, e é apoiada somente em um ombro procurou, desde jovem, reforço físico, especialmente para a musculatura da coluna.

\section{História de Vida e A Análise dos Processos da Aprendizagem Baseada em Práticas}

Com base nas trajetórias de vida relatadas a partir das entrevistas e do uso de vídeo como técnica projetiva foi possível organizar o cotidiano dos profissionais cinegrafistas e identificar as práticas envolvidas nesse cotidiano 
e processos de aprendizagem nelas imbricadas.

Para iniciar as reflexões a partir dos relatos dos personagens Pedro e Tarantino, pode-se perceber que, de alguma forma, ambos possuíam desde cedo a imagem em seu dia a dia. Mas como, afinal, esses indivíduos aprenderam a manusear equipamentos, fazer enquadramentos e segurar um equipamento de oito quilos em seus ombros?

A escolha para dar início à discussão da prática da construção do conhecimento, a partir dos próprios relatos dos cinegrafistas sobre sua percepção de como esse aprendizado ocorre, tem a intenção de instigar a curiosidade acerca das evidências dessa relação e de como ocorre esse processo.

O início do contato com os equipamentos ocorreu de diferentes maneiras entre os cinegrafistas, mas ambos, de algum modo, se envolviam informalmente com as câmeras para desenvolver habilidades de manuseio. Tarantino, por exemplo, relata que buscava montar os equipamentos e gravar tudo que estivesse à sua frente para ganhar segurança e confiança.

E pegar a câmera é bem difícil, porque a responsabilidade é toda tua, não tem ninguém pra dizer se é assim ou assado, por isso que eu treinei bastante. Terminava meu horário, as pessoas iam embora da emissora, eu pegava a chave da sala de equipamentos, montava todo o equipamento sozinho. Aí a gente montava todo o equipamento sozinhos, sem a equipe ver, e pegava uma fita, e gravava e depois ia ver o que a gente tinha feito (Tarantino).

A observação e o manuseio constituíram-se técnicas importantes de aprendizagem e permitiram aos entrevistados começarem sua inserção no meio e serem vistos pelos demais colegas. Junto com essa vivência durante o trabalho, a observação como forma de aprendizado não acontece apenas por assistir aos colegas de trabalho, mas também por notar outras realidades e buscar inspiração em outros meios. Pedro relata ter aprendido a perceber a televisão de forma diferente: "olhando assim a televisão com um olhar técnico, da minha área, da área de captação de imagem, tu começa, meio que a abrir a tua cabeça sabe" (Pedro).

O empenho fez com que, o que era até então, apenas mais um funcionário da emissora interessado em imagem buscasse novos conhecimentos. "Aí comecei a mexer, comecei a olhar, ler manuais, e pegar dicas com um ou outro colega assim. Na época era meio difícil assim, porque as pessoas não te liberavam a informação" (Pedro). A internet, os canais de televisão e outros formatos de programação constituem ferramentas essenciais para o desenvolvimento do indivíduo. Os entrevistados dizem sentir falta de chegar à emissora, olhar as imagens feitas, analisar os enquadramentos e trocar ideias com os colegas. Momentos como esses, segundos eles, ficam cada vez mais raros em função das pautas apertadas.

Hoje, após anos de profissão, é fácil visualizar o caminho de aprendizado percorrido por cada um. Semelhantes e diferentes, todos eles foram se envolvendo com a televisão e aprendendo, pela observação, a se comportar durante uma gravação, manusear o equipamento e escolher de que forma captar a imagem. Apesar da absorção de conhecimento, o começo da carreira dos entrevistados foi extremamente conturbado e pleno de situações 'inimagináveis'.

Mesmo que o profissional busque criar modos positivos de trabalho e de se relacionar com o repórter e com os equipamentos, o dia a dia da profissão o expõe a situações adversas, em que é necessário encontrar formas distintas e criativas de solucionar os problemas. Assim, "todo dia a gente aprende alguma coisa diferente. E aí tu aprende muita coisa com isso aí sabe, tu, em situações adversas assim tu sempre acaba aprendendo alguma coisa (...) que pra uma próxima vez tu já tem aquela alternativa" (Pedro).

Depois de algumas matérias sem foco ou escuras demais, cada um foi constituindo, a seu jeito, saberes que lhes permitiam mais fácil adaptação a diferentes situações. Com o tempo de exercício da profissão, os instintos e as próprias experiências de vida passam a fazer parte dos saberes desenvolvidos. O cinegrafista torna-se um indivíduo atento e desenvolve técnicas durante o dia a dia de trabalho e que não foram formalmente passadas a ninguém.

Tarantino relata um momento de destaque em sua profissão, na cobertura das manifestações de julho de 2013, em Porto Alegre, o qual exemplifica a relação entre o instinto natural e as práticas da profissão. Apesar de ter participado, antes do início dos protestos, de um curso ministrado pelo exército, Tarantino considera que o mais importante é o "instinto, a experiência de vida de cada um, a malandragem de cada um", além de ter "que ter um preparo psicológico bom" para não se abater ou se intimidar com as provocações, uma vez que a mídia também assume um papel importante no decorrer das manifestações. Mesmo tendo desenvolvido uma técnica para se proteger, que, conforme diz: "ninguém me ensinou, a gente tem que se adaptar na verdade", o cinegrafista foi vítima de um tiro de bala de borracha. "Eu sabia bem como me posicionar, isso foi bom. Tem uma coisa de instinto, de experiência de vida de cada um, da malandragem de cada um, de saber pô eu não entraria naquela 
http://www.revista.ufpe.br/gestaoorg

biboca, eu não vou entrar agora também” (Tarantino).

A dualidade entre a adrenalina da profissão e a voz da experiência andam lado a lado. Lidar com elas é uma competência que o profissional precisa desenvolver para resguardar sua segurança, a do equipamento e a da equipe e, ao mesmo tempo, obter a melhor imagem. Os entrevistados relatam que, no início da carreira, o cinegrafista é imaturo e não sabe ponderar corretamente os riscos da profissão, porém a experiência lhes permite obter esse equilíbrio.

É nas situações de convivência que os processos de aprendizado mais se destacam no grupo do cinegrafista, indo ao encontro dos conceitos de aprendizagem como um processo relacional e social (NICOLINI et al. 2003). A partir dos relatos dos entrevistados, é possível dizer que a vida de um cinegrafista se resume a dois grandes momentos, não separados, mas que se entrelaçam frequentemente. O primeiro refere-se ao relacionamento e ao aprendizado diário nas situações adversas em que são colocados. Elas exigem do profissional uma postura distinta e, em alguns casos, jamais antes praticada, embora amparada em práticas anteriores. Esta exigência resulta em práticas que precisam ser aprovadas pelos sentimentos e pelas sensações dos sujeitos que as praticam (STRATI, 2007). O segundo refere-se ao desafio diário e às relações de aprendizado estabelecidas, as quais são pautadas e sustentadas pela adrenalina e pela paixão profissional.

É notável que, segundo os entrevistados, "nada do que foi dito até agora nem do que será dito na sequência dessa pesquisa têm sentido se o sujeito não gostar do papel que desempenha". Por isso, todos os discursos são pautados no crescimento coletivo do conhecimento e na identificação do cinegrafista com a realidade que se apresenta. $\mathrm{O}$ sentimento de paixão pela profissão que surge entre os cinegrafistas faz possível relacionar as práticas vivenciadas com os processos de aprendizagem nelas envolvidos. No cotidiano desses profissionais é possível perceber como eles conseguem superar as inúmeras dificuldades da profissão e de sua trajetória - a formação como profissional, os riscos envolvidos durante as gravações, os imprevistos constantes. A identificação com a profissão se evidencia como requisito para superar os obstáculos e, consequentemente, como fator relevante, o qual influencia diretamente os processos de aprendizagem envolvidos na profissão, impulsionando ou limitando o aprendizado necessário para a prática cotidiana.

A existência de um olhar do cinegrafista que envolva afeto e sentimento pela profissão proporciona uma captura de imagem diferente do que se teria pelo olhar de um profissional sem essa identificação profissional. "E aí ele vai até o final da carreira dele medíocre, um profissional medíocre, ele vai conseguir se aposentar, exercer a profissão dele, mas não vai crescer na profissão, não vai aparecer na profissão, vai ser mais um na profissão" (Tarantino). Pelos discursos, percebe-se que um cinegrafista de destaque é aquele que inicia seu trabalho, no meio da televisão, sem necessariamente ser um cinegrafista, e vai desenvolvendo suas habilidades e percepções no dia a dia com os demais, no coletivo. A vivência do estilo de vida e dos hábitos ali instaurados é que guiará o comportamento e a adaptação do indivíduo. Mais do que por técnicas, a profissão do cinegrafista é pautada pela criatividade e pelo relacionamento, por isso o gostar e a identificação com o trabalho desempenhado são tão importantes para impulsionar o aprendizado e estabelecer as conexões necessárias.

A partir do momento em que se assume que as práticas não são apenas padrões recorrentes de ação, mas também padrões socialmente sustentados, entende-se que os indivíduos reproduzem não apenas trabalho, mas também a sociedade. Essa reprodução permite que o profissional crie um vínculo com a prática e seus participantes, formando uma relação de paixão, quer prazerosa ou dolorosa, que torna as práticas "socialmente sustentadas por julgamentos relacionados não apenas à utilidade, mas também à ética e à estética" (GHERARDI, 2013, p. 110).

No início das trajetórias dos entrevistados, seus mestres logo lhes ensinaram a praticar e compartilhar a apreciação da profissão com os demais, tornando possível aos praticantes comunicarem seus julgamentos e expressarem sua paixão pela prática. A partir da identificação dos praticantes, é possível visualizar a formação de identidades, ou seja, o vínculo existente entre os praticantes. Por fim, é possível perceber como a manutenção das práticas está relacionada com ambientes de tensão e repetição, que podem alterar a formação do gosto de um indivíduo. "O gosto molda as práticas de trabalho e as refina por meio da negociação e da refletividade, as quais suspendem o fluxo da ação a fim de intervir e saborear a prática e expressar um julgamento estético da mesma" (GHERARDI, 2013, p. 118).

Inúmeros pontos surgem ao longo dos discursos que evidenciam a formação dos saberes dos cinegrafistas e também as práticas de trabalho no dia a dia. A prática mais evidente, no grupo pesquisado, é a troca de experiências e a constituição da experiência do indivíduo, construída ao longo do tempo e que está aliada tanto a seu desenvolvimento profissional quanto pessoal. Os saberes dos cinegrafistas não estão pautados apenas na relação desenvolvida entre eles dentro da organização, mas também sofre influência de todos os outros saberes que compõem sua personalidade e lhe permitem mudar a forma de agir diante de diferentes situações, corroborando que aprender é relacional (NICOLINI et al., 2003). 
Nas falas dos entrevistados é possível perceber como o relacionamento representa a maior parte dos esforços e das preocupações dos profissionais. Segundo eles, os conceitos técnicos e as habilidades de manuseio da câmera são sempre semelhantes, independente da situação, e o que faz a diferença na execução de um bom material é o relacionamento do cinegrafista, quer com os demais cinegrafistas, quer com o repórter e a equipe de produção.

A construção do relacionamento entre os próprios cinegrafistas é algo que vai se constituindo com o transcorrer do tempo. A humildade e o interesse em aprender aparecem como características essenciais de um bom cinegrafista, que precisa se mostrar aberto a aprender com os demais profissionais. Antes mesmo de aprender a técnica da captação de imagem, é necessário aprimorar a capacidade de relacionamento. Um dos desafios diários é entender o outro e aprender a tirar o máximo dessa relação em prol da geração do conteúdo. "E o maior desafio é o mesmo que era antes, relacionamento, com repórter, com equipe, isso é difícil, era e é difícil ainda, então um exercício cotidiano, um exercício diário" (Tarantino). O trabalho em equipe é importante para estabelecer uma relação de contribuição e dedicação entre repórter, cinegrafista e auxiliar. A construção de uma matéria começa no estudo do conteúdo e da pauta, quando já inicia a troca entre o conhecimento do repórter sobre aquele conteúdo, suas expectativas e as possibilidades técnicas e de enquadramento do cinegrafista.

$\mathrm{O}$ estudo da aprendizagem com ênfase nas práticas a partir do uso da história de vida permitiu a análise dos processos de aprendizagem sob a ótica do fazer-saber, na qual pensar e agir não são tratados de forma dicotômica, mas como pertencentes a um único processo de aprendizagem (GHERARDI, 2000). Isto possibilitou ao pesquisador compreender os saberes existentes e que permeiam as práticas de trabalho das profissões consideradas de menor complexidade. A visão coletiva dos processos de aprendizagem, dos saberes que surgem a partir do fazer e da ação permite enxergar a cinegrafia como uma profissão que, apesar de pouco valorizada intelectualmente, sofre forte influência da interação social entre os sujeitos, da ação intencional e do raciocínio. O processo de aprendizagem dos cinegrafistas é um processo coletivo, permeado por práticas socialmente construídas, distanciando-se do conceito de práticas como ações que ocorrem repetidamente ou que são obrigatórias e previamente estabelecidas.

\section{Considerações Finais}

O método aqui adotado - histórias de vida - permitiu observar como os indivíduos se constituíram como profissionais e quais saberes foram sendo constituídos durante suas trajetórias de vida. Por meio dos relatos foi possível apreender o cotidiano dos cinegrafistas, suas práticas e relações com o trabalho e entre outros profissionais. Nesse sentido ressalta-se que foi através da análise da história de vida profissional dos pesquisados que se pode chegar a uma compreensão da dinâmica de suas práticas de trabalho e de seus processos de aprendizagem.

Um estudo do cotidiano de atores sociais com emprego da história de vida como método, associando entrevistas em profundidade ao uso de vídeo como estratégia, exigiu que o olhar do pesquisador se voltasse para uma dimensão, uma profissão, um grupo social que puderam ser identificados pelas práticas sociais que elaboram. "A vida cotidiana é caracterizada como o lugar das negociações do acontecimento pelos seres humanos e, ainda, como o lugar de disposição da existência pela construção sempre renovada da interface da natureza e da cultura" (BRIOSCHI, TRIGO, 1987). Relacionando o cotidiano e a narrativa de vida, no momento das entrevistas, os pesquisados estabeleceram uma reflexão de si e permitiram emergir em suas narrativas micro eventos que pontuaram a sua vida profissional cotidiana, além dos processos de aprendizagem que foram se constituindo, se transformando.

As relações que se estabelecem entre os atores de um grupo de profissionais de convívio, embora relatem sua experiência "individual", contribuem para que o pesquisador consiga compreender como sendo construção social da realidade. Sendo assim, foi necessário, para compreender as trajetórias profissionais dos cinegrafistas, situálas no contexto em que se desenvolveram, ou seja, considerar todo um conjunto de significações que constituem suas práticas e seus processos de aprendizagem.

Destaca-se ainda que os estudos da aprendizagem baseada em prática adotam a noção de aprendizagem em fluxo, processual e o método história de vida permite que esta noção seja respeitada, pois trata-se de um método de natureza processual, não no sentido de etapas cronológicas, mas de "uma vida em fluxo". Com base nas entrevistas dessa pesquisa é possível dizer que os saberes não se desenvolvem por meio de uma prática apenas, mas se constituem em uma rede de práticas interconectadas. Considerando os relatos, evidencia-se a noção de aprendizagem não dicotômica, em que saberes e práticas acontecem de forma processual, de coexistência, na qual o conhecimento não é visto descolado das práticas cotidianas (GHERARDI, 2000; STRATI, 2007).

Apesar dos avanços desse estudo, principalmente no que concerne à realidade dos cinegrafistas, outros estudos sobre o tema e sobre essa categoria profissional se fazem necessários, uma vez que são escassas as pesquisas que os consideram alvo da investigação. Dessa forma, sugere-se ainda como agenda pesquisas mais aprofundadas 
http://www.revista.ufpe.br/gestaoorg

sobre o dia a dia desses sujeitos, visando observar todos os artefatos que interferem em seu trabalho, como por exemplo questões relacionadas ao corpo e aos equipamentos.

\section{Referências}

ANTONELlO, C. S.; GODOY, A. S. A encruzilhada da aprendizagem organizacional: uma visão multiparadigmática. RAC, Curitiba, v.14, n. 2, p. 310-332, abr. 2010.

ANTONELLO, C. S. As formas de aprendizagem utilizadas por gestores no desenvolvimento de competências. In: ENCONTRO ANUAL DA ANPAD, XXVIII, 2004. Anais... Curitiba: Associação Nacional dos Cursos de Pós-Graduação em Administração, 2004.

ATKINSON, R. The life story interview. In GUBRIUM, J. F.; HOLSTEIN, J. A. (Org.). The handbook of interview research: context and method. London: Sage, 2002, p. 121-141.

BANKS, M. Dados visuais para pesquisa qualitativa. Porto Alegre: Artmed, 2009.

BECKER, H. S. The epistemology of Qualitative Research. 1997. Disponível em $<$ http://www.sfu.ca/ palys/Becker-EpistemologyOfQualitativeResearch.pdf> Acesso em: 18 jan. 2016.

BERTAUX, D. L'approche biographique: sa valité méthodologique,ses potentialités. Cahiers int sociol. p, 197225. 1980.

BORNAT, J. Oral History. In: SEALE, Clive et al. Qualitative Research Practice. London: Sage Publications, 2004.

BRIOSCHI, L. R, TRIGO, M. H. B. Relatos de vida em ciências sociais: considerações metodológicas. Ciência e Cultura, 1987, 39 (7): 631-7.

CHASE, S. Narrative Inquiry - Multiple Lenses, Approaches, Voices. In: DENZIN, Norman Kent; LINCOLN, Yvonna S. (Orgs). Collecting and Interpreting Qualitative Materials. Los Angeles: Sage Publications, 2008.

CHASE, S. Narrative inquiry: multiple lenses, approches, voices. In: DENZIN, Norman Kent. LINCOLN, Yvonna S. The Sage handbook of qualitative research. 3. ed. Thousand Oaks: Sage Publications, 2005.

CLOSS, L. Q.; ANTONELLO, C. S. História de vida: suas possibilidades para a investigação de processos de aprendizagem gerencial. Revista Eletrônica de Gestão Organizacional. Pernambuco, v. 10, n. 1, p. 105-137, jan/abr. 2012.

CORREIA, F. B. C.; FEITOSA, M. G. G.; VIEIRA, N. S. A consultoria como oportunidade de aprendizagem para as Organizações Não Governamentais: um estudo na cidade de Recife/PE. Rev. Adm. UFSM, Santa Maria, v. 3, n. 2, p. 245-259, mai./ago.2010.

DEMARTINI, Z. B. F. Histórias de vida na abordagem de problemas educacionais. In: SIMSON, Olga Rodrigues de Moraes Von. (Org.). Experimentos com histórias de vida: Itália-Brasil. São Pedro: Vértice, 1988.

DENZIN, N. K. Interpretive biography. Newbury Park: SAGE Publications, Inc., 1989.

DUARTE, M. Y. M. Estudo de caso. In: BARROS, Antonio (org.). Métodos e técnicas de pesquisa em comunicação. São Pedro: Atlas, 2006. p. 215 - 234.

FERRAROTTI, F. Sobre a autonomia do método biográfico. In: NÓVOA, António; FINGER, Mathias (Orgs.) O método (auto)biográfico e a formação. Lisboa: Ministério da Saúde. Depart. de Recursos Humanos da Saúde/Centro de Formação e Aperfeiçoamento Profissional, 1988. p. 17-34.

FONTANA, A.; FREY, J H. Interviewing: the art of science. In: DENZIN, Norman; LINCOLN, Yvonna. (org.). Handbook of qualitative research. London: Sage Publications.1994.

FONTANA, A.; FREY, J. H. The Interview: From Neutral Stance to Political Involvement. In: DENZIN, Norman Kent; LINCOLN, Yvonna S. (Orgs). Collecting and Interpreting Qualitative Materials. Los Angeles: Sage Publications, 2008.

FRISCH, M. Three Dimensions and More. Oral History Beyond the Paradoxes of Method. In: HESSE-BIBER, Sharlene N.; LEAVY, Patrícia. (Orgs). Handbook of Emergent Methods. New York: Guilford Press, 2008.

GHERARDI, S. Prática? É uma Questão de Gosto! Revista Interdisciplinar de Gestão Social, v.2, n.1, p. 107124, jan./abr. 2013.

GHERARDI, S. From organizational learning to practice-based knowing. Human relations, v. 54, n. 1, 2001.

GHERARDI, S. Practice-based theorizing on learning and knowing in organizations. Organization, v. 7, n. 2, p. 
211-223, 2000.

GIL, A. C. Métodos e técnicas de pesquisa social. 6. ed. São Pedro: Atlas, 2008.

HATCH, J. A.; WISNIEWSKI, R. Life history and narrative: questions, issues and exemplary works. In: HATCH, J. A; WISNIEWSKI, R. (Eds.). Life history and narrative. London: Routledge, 1995. p. 113-135.

JAIME, P.; GODOY, A. S.; ANTONELLO, C. S. História de vida: origens, debates contemporâneos e possibilidades no campo da administração. In: Encontro de Ensino e Pesquisa em Administração e Contabilidade I, 2007, Recife. Anais... Recife: EnEPQ, 2007.

JOSSO, M.-C. História de vida e projeto: a história de vida como projeto e as "histórias de vida" a serviço de projetos. Educação e Pesquisa, v. 25, n. 2. São Pedro, jul./dez. 1999.

KOLOSKOV, A. Managing Knowledge or Knowing in Practice? A critical review of perspectives on knowledge management. iSCHANNEL, v. 5, n. 1, p. 5-9, 2010.

LANKSHEAR, C.; KNOBEL, M. Pesquisa Pedagógica. Porto Alegre: ARTMED, 2008.

LOIZOS, P. Vídeo, Filme e Fotografias como Documentos de Pesquisa. In: BAUER, Martin W; GASKELL, George. Pesquisa Qualitativa com texto, imagem e som. Rio de Janeiro: Vozes, 2002. p. 137-155.

MAGESTE, G. S.; LOPES, F. T. L. O uso da história de vida nos estudos organizacionais. I Encontro de Ensino e Pesquisa em Administração e Contabilidade. Recife, 2007.

MAIER, G.; PRANGE, C.; VON ROSENTIEL, L. Psycological perspectives or organizational learning. In: DIERKS, M. et al. Organizational learning and knowledge. Oxford: Oxford University Press, 2001, cap. 1, p. 14-34.

MERRIAM, S. B. Qualitative research and case study applications in education. United States of America: 1998.

MORAES, L. V. S. A dinâmica da aprendizagem gerencial - o caso do Hospital Moinhos de Ventos. 2000. 233f. Dissertação (Mestrado em Engenharia da Produção) - Programa de Pós-Graduação em Engenharia da Produção, Centro Tecnológico, Universidade Federal de Santa Catarina, Florianópolis, 2000.

NICOLINI, D.; GHERARDI, S.; YANOW, D. Introduction: Toward a Practice-Based View of Knowing and Learning in Organizations. In: NICOLINI, Davide; GHERARDI, Silvia; YANOW, Dvora. Knowing In Organizations: A Practice-Based Approach. New York: M.E. Sharpe, 2003.

NOGUEIRA, M. L. M. Mobilidade psicossocial: a história de Nil na cidade vivida. 2004. 145 f. Dissertação (Mestrado em Psicologia Social) - Departamento de Psicologia, Faculdade de Filosofia e Ciências Humanas, Universidade Federal de Minas Gerais, Minas Gerais, 2004.

PARANÁ, D. Filho do Brasil: de Luiz Inácio a Lula. São Pedro: Ed. Xamã, 1996.

PAULILO, M. A. S. A Pesquisa Qualitativa e a História de Vida. Serviço social em revista, 1999, v. 1, n.1, 135 - 148. Londrina.

PERAZZO, P. F.; BASSI, C. S. Possibilidades do método de história oral nos estudos em administração. I Encontro de Ensino e Pesquisa em Administração e Contabilidade. Recife, 2007.

PLUMMER, K. Documents of life. London: Sage Publications, 2001.

POLKINGHORNE, D. E. Narrative configuration in qualitative analysis. In: HATCH, J. Amos. (Ed.) Life history and narrative. London: Routledge Falmer, 1995.

PRANGE, C. Aprendizagem organizacional: desesperadamente em busca de teorias? In: EASTERBY-SMITH, Mark et al. Aprendizagem organizacional e organização de aprendizagem. São Pedro: Atlas, 2001.

QUEIROZ, M. I. P. Relatos orais: do "indizível" ao "dizível". In: SIMSON, Olga Rodrigues de Moraes Von. (Org.). Experimentos com histórias de vida: Itália-Brasil. São Pedro: Vértice, 1988.

SPINK, M. J.; LIMA, H. Rigor e visibilidade: a explicitação dos passos da interpretação. In: SPINK, Mary Jane (org.). Práticas discursivas e produção de sentidos no cotidiano: aproximações teóricas e metodológicas. Rio de Janeiro: Centro Edelstein de Pesquisas Sociais, 2013.

STRATI, A. Organização e estética. Rio de Janeiro: Editora FGV, 2007.

\footnotetext{
${ }^{i}$ Operador de vídetoeipe é uma função extinta. Esta era a função de um técnico que acompanhava o cinegrafista para manusear o aparelho em que estava a fita de gravação.
} 
O Método de História de Vida: Contribuições para a Compreensão de Processos de Aprendizagem nas Organizações

Revista Gestão.Org, v. 15, n. 1, 2017. p. 22-36

ISSN 1679-1827

http://www.revista.ufpe.br/gestaoorg

ii Time-lapse é um processo cinematográfico em que a frequência de cada foto por segundo de filme é muito menor do que aquela em que o filme será reproduzido. Assim, quando visto a uma velocidade normal, o tempo parece correr mais depressa. 